\title{
Effects of Vocational Consultation on Relapse Rate and Hope among Drug Dependents in Bojnurd, Iran
}

\author{
Seyed Kaveh Hojjat ${ }^{1}$, Roghieh Raufpoor ${ }^{2}$, Mina Norozi Khalili ${ }^{3}$, Mahin Hamidi ${ }^{4}$, Mahsa Danesh ${ }^{5}$, Hadiseh
}

Monadi Ziarat ${ }^{6}$

${ }^{1}$ MD, Psychiatrist, Assistant Professor, Addiction and Behavioral Sciences Research Center, North Khorasan University of Medical Sciences. Bojnurd, Iran

${ }^{2}$ MA of Vocational Counseling, Islamic Azad University, Ghuchan Branch, Ghuchan, Iran

${ }^{3}$ MD, Department of Community Medicine and Ethics, Faculty of Medicine, North khorasan University of Medical Sciences, Bojnurd, Iran

${ }^{4}$ MA of Clinical Psychology, Addiction and Behavioral Sciences Research Center, North khorasan University of Medical Sciences, Bojnurd, Iran

${ }^{5} \mathrm{PhD}$ Student of Counseling, Islamic Azad University, Bojnurd Branch, Bojnurd, Iran

${ }^{6}$ MSc of Educational Nursing, Addiction and Behavioral Sciences Research Center, North khorasan University of Medical Sciences, Bojnurd, Iran

\section{Type of article: Original}

\begin{abstract}
Introduction: Drug addiction is one of the most flagrant social damages that can easily enervate the sociocultural foundation of a country as well as endanger human dynamism. One of the prevalent problems among most addicted people is their low hope and relapse of drug dependence. The aim of this study was to assess the effect of vocational consultation (for training on problem-solving skills) on hope and relapse rate of patients treated in methadone maintenance clinics.

Methods: This experiment was conducted on 60 drug abusers treated in a methadone maintenance program in drug addiction centers in Bojnurd, Iran, in 2014. The patients were randomly and equally allocated into two study and control groups. All patients completed the Miller Hope Questionnaire before and after the intervention. Ten sessions of vocational consultation were held for the study group while the control group received no special treatment. Patients were followed up on for relapses for six months. Data were analyzed using SPSS (version 16) and the paired-samples t-test technique.

Results: The results indicated that the mean and standard deviation of hope on the pre-test in the study group increased on the post-test (from $\mathrm{M}=175.5, \mathrm{SD}=31.8$, to $\mathrm{M}=198.5, \mathrm{SD}=20.4$ ), while in the control group the mean of hope decreased from the pre-test to past-test stage ( $M=184.7, S D=27.7$, to $M=183.3, S D=26.1)$, showing a significant relationship, $\mathrm{t}(56)=5.657, \mathrm{p}<0.05$. The relapse rate was not significantly different in the two groups.

Conclusion: The vocational consultation positively affects hope among drug dependents but did not affect their relapse rate during the six-month follow-up. Increasing the hope in these groups of patients may be effective in other aspects of treatment success in long-term follow-up.

Keywords: vocational consultation, hope, relapse, drug dependency, problem-solving skills
\end{abstract}

\section{Introduction}

\subsection{Background and study logic}

Drug addiction is considered a physical, mental, and social disease that endangers all the life dimensions of individual, family, and social health due to its growing nature (1). In fact, this issue is a significant individual and social problem that not only has physical and mental effects on the drug abuser, but also endangers the social, economic, political, and cultural health of the society and can also lead to some social and hygienic harm, like

\section{Corresponding author:}

Dr. Mina Norozi khalili, Department of Community Medicine, Faculty of Medicine, North khorasan University of Medical Sciences, Bojnurd, Iran. Tel: +98.58322311008, Email: minanorouzikhalili@gmail.com

Received: September 20, 2015, Accepted: November 15, 2015, Published: January 2016

iThenticate screening: November 15, 2015, English editing: December 10, 2015, Quality control: January 05, 2016 (C) 2015 The Authors. This is an open access article under the terms of the Creative Commons Attribution-NonCommercialNoDerivs License, which permits use and distribution in any medium, provided the original work is properly cited, the use is non-commercial and no modifications or adaptations are made. 
wasting the drug abuser's assets; increasing violence, delinquency, unemployment, and HIV; and increasing the rate of mental disorders and suicide $(2,3)$. Being recrudescent, drug addiction leaves a great burden on the society's economy and also irreparably damages the mental health of drug abusers' families (4). New findings have shown that the rate of drug dependence and drug abuse is $16.7 \%$ for people over the age of 18 in the United States (5). Furthermore, based on the latest statistics from 2006 and confirmed by the government of Islamic Republic of Iran, there are 3,761,000 drug abusers in Iran (6).

In fact, there is a significant correlation among drug abuse and mental disorders like depression (7). Being so influential, hopefulness motivates people to achieve their individual ambitions and goals (8). Compared with those who have a lower level of hope, those who have a higher level are more self-confident in achieving their goals and are more capable of reaching greater ambitions (9). A variety of research has demonstrated that, when unemployment increases, corruption intensifies whereas appropriate employment and job satisfaction result in people's joy, which leads to an increase in their hopefulness (10). Employment is sometimes regarded as a problematic issue and sometimes as a problem-solving matter as it requires people to be awake during the night, which is one of the most influential factors in drug abuse as employees feel tired and experience disruptions in their biological habits, creating depressed feelings (11). Drug abusers have deficient skills in life and apply inefficient problem-solving approaches when they face common problems. Thus, in recent decades, many researchers have demonstrated the need to consider psychological interventions to improve drug abusers' life quality (12). The studies have shown significant correlations between life quality and psychological variables like stress and social support; facing stressful situations often causes distress, decreases individual and family security and health, and reduces the life quality level (13-15). Different methods of therapy interventions have been proposed for drug addiction. These interventions can be divided into two categories: medical and psychological (16). Psychological interventions help drug abusers recognize and implement strategies of behavior alteration related to abusing drugs and increase their motivation to change their behaviors (17). Approximately half of drug abusers who start treatment do not even complete the first month, resulting in poor results from the treatment process (18). Behavioral experts believe that one of the most helpful programs for people to have a better and healthier life is life skills training programs; drug abusers need to know about their illness and how it will damage them and their families. Individual and group consultations are also important treatment processes whose goal is to create skills that support awareness and long-term treatment course. Studies on the effects of life skills training on the prevention and treatment of drug abuse have demonstrated that training is positively related to drug abuse prevention and treatment (19-21). Another effective approach for treating drug abuse is vocational consultation and the creation of job opportunities that increase people's self-confidence. By increasing self-confidence, job consultation helps these individuals achieve success. Regarding the prevalent abuse of drugs in our country and using the above-mentioned experiences, vocational consultation can be used in the course of treatment (22).

\subsection{Objectives}

As drug addiction is a current issue facing society and because of the lack of comprehensive studies in this field, the general objective of this study was to assess the effectiveness of job consulting training methods on patients treated with methadone maintenance. The specific objectives were 1) to determine this effectiveness on relapse rate and 2) to assess the effectiveness on hope of patients treated with methadone maintenance in Bojnurd, Iran.

\section{Material and Methods}

\subsection{Research design}

The present study is an experimental research that examines two groups via a pre-test stage and a post-test stage. The participants of the study are all heroin-dependent people treated in methadone maintenance clinics in Bojnurd, a northeastern city in Iran, in 2014.

\subsection{Sampling}

The sample of the study includes 60 men going through methadone maintenance treatment. Sampling was done according to the available samples based on the job complaints that they discussed during the first session of consultation in the addiction treatment centers, and samples were chosen from among 8 methadone maintenance clinics in Bojnurd and introduced by their consultants. After getting permission and confirming that they met the required criteria, the researchers started studying the participants and then randomly divided them into two groups of 30 (i.e., a study and a control group) using computer-generated random numbers for randomization. The intervention process was done in the welfare organization in Bojnurd. The participants took part in the class in groups. The 
participants were between 20 and 45 years old. The inclusion criteria were starting methadone treatment at least six months prior, the existence of a complaint about a job based on the addicted statement, and being male.

\subsection{Measurement tools}

This research used a demographic information checklist, the Miller hope questionnaire, and a morphine urinary sample test. The first questionnaire asks for demographic information such as age, marital status, education level, employment, and salary. The Miller Hope Questionnaire includes 48 items whose answers contain a range of five options (completely disagree (1), quite disagree (2), no idea (3), quite agree (4), completely agree (5)). Each participant was scored according to the options that he thought best fit him. The score of each sentence can range from 1 to 5, and total scores can range from 48 to 240 (23). A person who achieves 48 on this test is completely depressed and distressed; someone who achieves 240 is fully hopeful in life. The 14 items of the Miller Hope Questionnaire imply negative items scored from 5 to 1 in the scoring process. The Persian translated version of the Miller Hope Questionnaire was evaluated. The reliability of the questionnaire translated by Shoa'a Kazemi, examining a sample group of 35 people suffering from cancer, was $79 \%$ using Cronbach's alpha. Furthermore, the face and content validity of the questionnaire was evaluated and approved by a group of expert psychology professors. The urinary morphine test of the samples was also done in the addiction treatment centers using a urinalysis; its validity was confirmed by the treatment centers under study. Urinary morphine tests are conducted every two weeks in methadone maintenance clinics based on the MMT program, and relapse is diagnosed by two positive morphine tests or the self-discontinuation of treatment. Participants were followed for six months after intervention.

\subsection{Data collection}

Participants were provided with some explanation of the study. All participants then completed the permission form to take part in the study. Before doing the intervention, all selected participants completed the Miller Hope Questionnaire. Participants were then divided into two groups, a study and a control group. The study group was exposed to the independent variable but the control group was not affected by any variables. The members of the study group had the opportunity to benefit from 10 sessions of job consultation-targeted training and problemsolving skills while the members of the control group did not. At the end of the 10 sessions, the post-test stage was done in both the study and control groups, during while two scales were administered for both groups. The same test was done in Coviello's study (24).

\subsection{Research ethics}

The researcher started the study by getting a permission letter issued by the North Khorasan Addiction research center, confirming the letter with the ethics committee of the regional medical university, and doing other cooperative tasks with others sections. The Ethical Committee of Islamic Azad University, Ghuchan Branch, Ghuchan, Iran, approved the study (letter No. 92/45368/43).

\subsection{Statistical analyses}

Data analysis was done using SPSS software (version 16). The collected data were analyzed using the descriptive and deductive statistical approaches. To descriptively analyze the data, the researcher used statistics like number, mean, and standard deviation while the researcher employed a paired-samples t-test for the comparison of the means for deductive analysis.

\section{Results}

The present study included 60 participants divided into two groups of 30 for the study and control groups. All participants completed the pre-test stage form, and the study group received the training program. During the posttest stage, two people exited the group and did not complete the post-test stage questionnaire. Thus, 28 people of the study group succeeded in completing the training program. All members of the control group completed both the pre-test and post-test stages. The participants ranged in age between 20 and 45 years old. The mean and standard deviation of the age of the study group was $(32.9 \pm 5.7)$ and of the control group was (31.7 \pm 5$)$. In addition, $89.2 \%$ of the members of the study group and $96.6 \%$ of the control group were married while $3.7 \%$ of the participants of the study group were single and there was no single person in the control group. In terms of marital status, the groups were not significantly different from each other ( $p>0.05$ ) (Table 1). Furthermore, $25 \%$ of the members of the study group and $43.3 \%$ of the control group held diplomas or higher education degrees; only $7 \%$ of all group members were illiterate. Considering the achieved results, the groups were not significantly different from each other ( $\mathrm{p}>0.05$ ) (Table 1). In addition, $46.4 \%$ of the study group had their own private business, $21.4 \%$ of them were 
workers, and $28.6 \%$ were unemployed, compared to $43.3 \%, 43.3 \%$, and $10 \%$, respectively, in the control group. Therefore, the two groups were not significantly different $(\mathrm{p}>0.05)$ (Table 1$)$. Table 1 also shows the descriptive statistics related to the marital status, education level, and employment status of the two groups. The achieved results show no significant difference between the two groups, and both groups had the same situation. The mean of the pre-test stage equaled 175.5 and 184.7 in the study group and control group, respectively, demonstrating that no significant difference exists between the two groups in the pre-test stage ( $>0.05)$ (Table 2).

Table1. Descriptive Statistics Related to the Indexes of Marital Status, Education Level, and Employment Status of the Participants

\begin{tabular}{|c|c|c|c|c|c|c|}
\hline \multirow{2}{*}{\multicolumn{2}{|c|}{ Index }} & \multicolumn{2}{|c|}{ Study group } & \multicolumn{2}{|c|}{ Control group } & \multirow[t]{2}{*}{ p-value } \\
\hline & & $\mathrm{n}$ & $\%$ & $\mathrm{n}$ & $\%$ & \\
\hline \multirow{3}{*}{ Marital status } & Married & 25 & 89.2 & 29 & 96.6 & \multirow[t]{3}{*}{0.397} \\
\hline & Divorced & 2 & 7.1 & 1 & 3.4 & \\
\hline & Single & 1 & 3.7 & 0 & 0 & \\
\hline \multirow{6}{*}{$\begin{array}{l}\text { Education } \\
\text { Level }\end{array}$} & Illiterate & 2 & 7.1 & 0 & 0 & \multirow{6}{*}{0.478} \\
\hline & Elementary school & 5 & 17.9 & 5 & 16.7 & \\
\hline & Guidance school & 8 & 28.6 & 9 & 30 & \\
\hline & High school & 6 & 21.4 & 3 & 10 & \\
\hline & Diploma & 6 & 21.4 & 10 & 33.3 & \\
\hline & University & 1 & 3.6 & 3 & 10 & \\
\hline \multirow{4}{*}{$\begin{array}{l}\text { Employment } \\
\text { Status }\end{array}$} & Unemployed & 8 & 28.6 & 3 & 10 & \multirow[t]{4}{*}{0.148} \\
\hline & Worker & 6 & 21.4 & 13 & 43.3 & \\
\hline & Clerk & 1 & 3.6 & 1 & 3.3 & \\
\hline & Private business & 13 & 46.6 & 13 & 43.3 & \\
\hline
\end{tabular}

Table 2. Results of Independent $t$-Test in the Pre-test Stage of Mean Hope in Two Groups

\begin{tabular}{|l|l|l|l|l|l|l|}
\hline \multicolumn{2}{|l|}{ Group } & Mean & $\mathrm{SD}^{1}$ & $t$-statistics & $\mathrm{df}^{2}$ & $\mathrm{p}$-value \\
\hline Pre-test stage & Study & 175.5 & 31.8 & -1.173 & 56 & 0.246 \\
\cline { 2 - 7 } & Control & 184.7 & 27.7 & & & \\
\hline
\end{tabular}

1: Standard deviation; 2: Degree of freedom

The results further indicated that the mean and standard deviation of hope on the pre-test increased in the post-test stage for the study group (from $\mathrm{M}=175.5, \mathrm{SD}=31.8$, to $\mathrm{M}=198.5, \mathrm{SD}=20.4$ ), but decreased for the control group (from $\mathrm{M}=184.7, \mathrm{SD}=27.7$, to $\mathrm{M}=183.3, \mathrm{SD}=26.1$ ), showing a significant relationship, $\mathrm{t}(56)=5.657, \mathrm{p}<0.05$ (Table $3)$. In order to control the reduction of the relapse scale, both groups took the morphine test. The results showed that neither the study and control groups were significantly different from each other regarding the relapse of drug addiction. In other words, the job consultation training was not effective in reducing the relapse of drug addiction and was ineffective $(\mathrm{p}=0.612)$ (Table 4$)$.

Table 3. Results of Paired $t$-Tests of Training's Effectiveness on Hope Scale in Two Groups (Miller Hope Questionnaire)

\begin{tabular}{|l|l|l|l|l|}
\hline Group & Pre-test & Post-test & $t$-statistics & $\mathrm{p}$-value \\
\hline Study & $175.5 \pm 31.8$ & $198.5 \pm 20.4$ & 5.657 & 0.034 \\
\hline Control & $184.7 \pm 27.7$ & $183.3 \pm 26.1$ & & \\
\hline
\end{tabular}

Table 4. Results of Vocational Consultation Training's Effectiveness on Relapse in Two Groups

\begin{tabular}{|c|c|c|c|c|c|}
\hline \multirow[t]{2}{*}{ Relapse Rate } & \multicolumn{2}{|c|}{ Study group } & \multicolumn{2}{|c|}{ Control group } & \multirow[t]{2}{*}{ p-value } \\
\hline & $\mathrm{n}$ & $\%$ & $\mathrm{n}$ & $\%$ & \\
\hline Relapse & 1 & 3.6 & 3 & 10 & \multirow{3}{*}{0.612} \\
\hline No relapse & 27 & 96.4 & 27 & 90 & \\
\hline Total & 28 & 100 & 30 & 100 & \\
\hline
\end{tabular}




\section{Discussion}

The main purpose of the current study was to determine the effectiveness of vocational consultation aimed at enhancing drug dependents' problem-solving skills to increase their hope and decrease their chance of relapse in patients treated with methadone maintenance in addiction treatment centers in Bojnurd, Iran. The findings of the present study showed that vocational consultation positively affects individuals' hope. Vocational consultation increased hope among the study group compared with the control group. The mean of hope in the study group was 175.5 in the pre-test stage and increased to 198.5 in the post-test stage. In the control group, the mean of hope was 184.7 in the pre-test stage, which decreased to 183.3 in the post-test stage. Thus, problem-solving skill training increased hope among drug abusers.

Although the researcher looked for literature on the effect of vocational consultation on hope and the reduction of relapse of drug addiction in national and international sources, he could not find any related research. Nevertheless, the results achieved by Staines (25), who evaluated the effectiveness of job rehabilitation as a supportive factor on drug abusers treated with methadone, showed the positive effect of this factor on finding jobs for the study participants. Another study of drug abusers treated with methadone was conducted by Kidorf (26), who evaluated the effectiveness of the behavioral approach in increasing patients' self-confidence to find a job; the results showed that this factor effectively increased full-time jobs throughout the year, increased the number of work hours, and decreased job shifts. In 2004, Magua et al. (27) systematically reviewed the effectiveness of job consultation on drug abusers under treatment. A review of studies from the three past decades demonstrated that job factor positively affected the success of treating drug abusers. Zanis et al. (28) studied the effectiveness of problem-solving skills on the function of drug abusers treated with methadone. The findings showed that job consultation had no effect on the drug abusers' job functions. These findings are not consistent with the results of the current study. In recent years, many studies have examined different approaches to treating drug-dependent patients and their effects. These approaches include treating with methadone, detoxification, and duration of treatment. Unfortunately, the main problem is that, even if the duration of not using drugs after treatment is long, the probability of relapse into drug addiction is high (29). Some scientists have talked about the existence of a relationship between life stresses and the relapse of drug addiction, concluding that group treatment is an effective approach in the prevention of drug addiction relapse (30-32). The results of the present study show that vocational consultation is not effective in the reduction of drug addiction relapse. Comparing the present study's finding with the theoretical and experimental findings, it becomes clear that these findings are consistent with each other regarding the effect of job consultation and the application of life skills on drug addiction relapse. However, patients' condition evaluated just six months after our intervention and vocational consultation need longer follow-up time to determine the impact of vocational training. Indeed, the results of Shargh's study showed that individual factors like feeling lonely (36\%), family factors and improper relationships between parents and children (17.5), social factors like befriending drug abusers $(35.5 \%)$, economic factors like unemployment $(34.6 \%)$, and cultural factors like not having appropriate recreation and entertainment (40.4\%) are of great importance (33). Amini et al.'s (34) study examined social and environmental factors related to the relapse of drug addiction among drug abusers in governmental drug addiction centers in Hamadan. The results showed that, from drug abusers' point of view, critical interpersonal, employment, and economic factors related to drug addiction relapse are, respectively, befriending drug abusers (87.5\%), unemployment $(70.9 \%)$, and poverty $(67.7 \%)$. This findings demonstrates the effect of job consultation on drug addiction relapse. Therefore, it can be concluded that more time is needed to review and confirm the findings.

The present study shows that the short-term impacts of vocational consultation are effective as a controlling approach. Confirming the effectiveness of vocational consultation and problem-solving skills program on the increase of hope, the findings also helped explain the mechanism of this program and showed that the researcher needs to observe the effects among participants for 6 to 12 months in order to obtain more precise results. One of the most important issues in follow-up studies is the time duration of the follow-up. Although, we assessed both hope and relapse rate in patients treated with methadone as a positive point of this study, the six-month follow-up time was a limitation.

\section{Conclusions}

Job consultation positively affects the hope of drug dependents, but does not affect the relapse rate during a sixmonth follow-up period. Drug addiction intensifies family problems and negatively affects drug abusers as well as their family members and relatives. It is suggested that, while providing the required facilities and using expert psychologies, drug addiction centers should apply this treatment approach to improve drug abusers' life quality and professionally present a job consultation program. Furthermore, additional similar research should be conducted 
with more participants to explore other psychological problems, resulting in a better understanding of this treatment approach.

\section{Acknowledgments:}

This manuscript was part of a research conducted in Islamic Azad University, Ghuchan Branch, Ghuchan, Iran (Ref. No. 92/45368 and ethical committee approval No. 92/45368/43). The authors acknowledge all participants in the study and also declare no conflict of interest.

\section{Conflict of Interest:}

There is no conflict of interest to be declared.

Authors' contributions:

All authors contributed to this project and article equally. All authors read and approved the final manuscript.

\section{References}

1) Le Moal M, Koob GF. Drug addiction: pathways to the disease and pathophysiological perspectives. Eur Neuropsychopharmacol. 2007; 17(6-7): 377-93. doi: 10.1016/j.euroneuro.2006.10.006, PMID: 17169534.

2) Lalaguna JLP, Ribas CC, Aymerich M. Addictions: A Need for Specific Education. Procedia-Social and Behavioral Sciences. 2014; 141: 160-5. doi: 10.1016/j.sbspro.2014.05.029.

3) Reed E, Amaro H, Matsumoto A, Kaysen D. The relation between interpersonal violence and substance use among a sample of university students: Examination of the role of victim and perpetrator substance use.. Addict Behav. 2009; 34(3): 316-8. doi: 10.1016/j.addbeh.2008.10.015. PMCID: PMC4497789

4) Volkow ND, Baler RD, Goldstein RZ. Addiction: pulling at the neural threads of social behaviors. Neuron. 2011; 69(4): 599-602. doi: 10.1016/j.neuron.2011.01.027, PMID: 21338873.

5) Bermas H, Masooleh SMT. Review and Comparison of Affective Family Factors in Prevention of Drug Abuse in View of University Masters, Mental Health Specialist and Families. Procedia-Social and Behavioral Sciences. 2011; 12(0): 520-35. doi: 10.1016/j.sbspro.2011.02.064.

6) Miri Aashtiani E. Sociology of addiction in Iran today. Tehran: Mohajer Publications; 2006.

7) Marefat M, Peymanzad H, Alikhajeh Y. The Study of the Effects of Yoga Exercises on Addicts' Depression and Anxiety in Rehabilitation Period. Procedia-Social and Behavioral Sciences. 2011; 30(0): 1494-8. doi: 10.1016/j.sbspro.2011.10.289.

8) Snyder CR, Ilardi SS, Cheavens J, Michael ST, Yamhure L, Sympson S. The role of hope in cognitivebehavior therapies. Cognitive therapy and Research. 2000; 24(6):747-62. doi: 10.1023/A:1005547730153.

9) Jackson R, Wernicke R, Haaga DAF. Hope as a predictor of entering substance abuse treatment. Addictive Behaviors. 2003; 28(1): 13-28. doi: 10.1016/S0306-4603(01)00210-6.

10) Kang SY, Magura S, Blankertz L, Madison E, Spinelli M. Predictors of engagement in vocational counseling for methadone treatment patients. Subst Use Misuse. 2006; 41(8): 1125-38. doi: 10.1080/10826080500411551, PMID: 16798680.

11) Ekhtiari H. Guide to understanding and treatment of addiction. Tehran: Arjmand; 2012.

12) Lash JP, Wang X, Greene T, Gadegbeku CA, Hall Y, Jones K, et al. Quality of life in the African American Study of Kidney Disease and Hypertension: effects of blood pressure management. Am J Kidney Dis. 2006; 47(6): 956-64. doi: 10.1053/j.ajkd.2006.02.175, PMID: 16731290.

13) Paterson C, Jones M, Rattray J, Lauder W. Exploring the relationship between coping, social support and health-related quality of life for prostate cancer survivors: A review of the literature. Eur J Oncol Nurs. 2013; 17(6): 750-9. doi: 10.1016/j.ejon.2013.04.002, PMID: 23732014.

14) Sinha R, Jastreboff AM. Stress as a common risk factor for obesity and addiction. Biol Psychiatry. 2013;73(9):827-35. doi: 10.1016/j.biopsych.2013.01.032, PMID: 23541000.

15) Hassanbeigi A, Askari J, Hassanbeigi D, Pourmovahed Z. The Relationship between Stress and Addiction. Procedia-Social and Behavioral Sciences. 2013; 84(0): 1333-40. doi: 10.1016/j.sbspro.2013.06.752.

16) Potenza MN, Sofuoglu M, Carroll KM, Rounsaville BJ. Neuroscience of behavioral and pharmacological treatments for addictions. Neuron. 2011; 69(4): 695-712. doi: 10.1016/j.neuron.2011.02.009, PMID: 21338880.

17) Carroll KM, Onken LS. Behavioral therapies for drug abuse. Am J Psychiatry. 2005; 162(8): 1452-60. doi: 10.1176/appi.ajp.162.8.1452, PMCID: PMC3633201. 
18) Stark MJ. Dropping out of substance abuse treatment: A clinically oriented review. Clinical psychology review. 1992; 12(1): 93-116. doi: 10.1016/0272-7358(92)90092-M.

19) Skara S, Sussman S. A review of 25 long-term adolescent tobacco and other drug use prevention program evaluations. Prev Med. 2003; 37(5): 451-74. doi: 10.1016/S0091-7435(03)00166-X, PMID: 14572430.

20) Botvin GJ. Preventing drug abuse in schools: Social and competence enhancement approaches targeting individual-level etiologic factors. Addict Behav. 2000; 25(6): 887-97. doi: 10.1016/S0306-4603(00)001192, PMID: 11125777.

21) Wenzel V, Weichold K, Silbereisen RK. The life skills program IPSY: Positive influences on school bonding and prevention of substance misuse. J Adolesc. 2009; 32(6): 1391-401. doi: 10.1016/j.adolescence.2009.05.008, PMID: 19596147.

22) Comerford AW. Work Dysfunction and Addiction: Common Roots. J Subst Abuse Treat. 1999; 16(3): 24753. doi: 10.1016/S0740-5472(98)00070-1, PMID: 10194742.

23) Miller JF, Powers MJ. Development of an instrument to measure hope. Nurs Res. 1988; 37(1): 6-10, PMID: 3340583.

24) Coviello DM, Zanis DA, Lynch K. Effectiveness of vocational problem-solving skills on motivation and job-seeking action steps. Subst Use Misuse. 2004; 39(13-14): 2309-24, PMID: 15603006.

25) Staines GL, Blankertz L, Magura S, Bali P, Madison EM, Spinelli M, et al. Efficacy of the Customized Employment Supports (CES) model of vocational rehabilitation for unemployed methadone patients: Preliminary results. Subst Use Misuse. 2004; 39(13-14): 2261-85. doi: 10.1081/JA-200034618, PMID: 15603004.

26) Kidorf M, Disney ER, King VL, Neufeld K, Beilenson PL, Brooner RK. Prevalence of psychiatric and substance use disorders in opioid abusers in a community syringe exchange program. Drug Alcohol Depend. 2004; 74(2): 115-22. doi: 10.1016/j.drugalcdep.2003.11.014, PMID: 15099655.

27) Magura S, Staines GL, Blankertz L, Madison EM. The effectiveness of vocational services for substance users in treatment. Subst Use Misuse. 2004; 39(13-14): 2165-213. doi: 10.1081/JA-200034589, PMID: 15603001.

28) Zanis DA, Coviello D, Alterman AI, Appling SE. A community-based trial of vocational problem-solving to increase employment among methadone patients. J Subst Abuse Treat. 2001; 21(1): 19-26. doi: 10.1016/S0740-5472(01)00177-5, PMID: 11516923.

29) Yan Y, Nabeshima T. Mouse model of relapse to the abuse of drugs: procedural considerations and characterizations. Behav Brain Res. 2009; 196(1):1-10. doi: 10.1016/j.bbr.2008.08.017, PMID: 18782591.

30) Somov PG. A psychodrama group for substance use relapse prevention training. The Arts in Psychotherapy. 2008; 35(2): 151-61. doi: 10.1016/j.aip.2007.11.002.

31) Litt MD, Kadden RM, Cooney NL, Kabela E. Coping skills and treatment outcomes in cognitivebehavioral and interactional group therapy for alcoholism. J Consult Clin Psychol. 2003; 71(1): 118. doi: 10.1037/0022-006X.71.1.118, PMID: 12602432.

32) Latimer WW, Newcomb M, Winters KC, Stinchfield RD. Adolescent substance abuse treatment outcome: The role of substance abuse problem severity, psychosocial, and treatment factors. J Consult Clin Psychol. 2000; 68(4): 684. doi: 10.1037/0022-006X.68.4.684, PMID: 10965643.

33) Shargh A, Shakibi A, Neysari R, Alilou L. Factors affecting the relapse of drug addiction in addiction centers of West Azarbaijan Province. Urmia Medical Journal. 2011; 22(2): 129-36.

34) Amini K, Amini D, Afshar Moghaddam F, Azar M. Study of social andenvironmental factors associated with relapse in substance abusers of addiction centers of Tehran. Journal of Zanjan University Of Medical Sciences And Health Services. 2003; 11(45): 41-55. 